\title{
HERRAMIENTAS PARA INTERVENIR EN EL PATRIMONIO: EL INVENTARIO DE PATRIMONIO INDUSTRIAL DE CASTILLA Y LEÓN
}

Paz BENITO DEL POZO

Departamento de Geografía y Geología. Universidad de León

\section{INTRODUCCIÓN}

El patrimonio industrial se percibe como un recurso sobre el que las Administraciones Públicas tratan de intervenir para rescatar elementos considerados parte de un paisaje cultural, muy valioso para dinamizar territorios marcados por la atonía y para activar políticas de desarrollo local y urbano. A tal fin se hace preciso disponer de un inventario riguroso de vestigios los industriales y los paisajes a los que van asociados, paso previo para la planificación y puesta en valor de dicho recurso territorial, vinculado a la historia industrial de espacios muy diversos.

En Castilla y León se dispone de una herramienta, los inventarios provinciales de patrimonio industrial, que este trabajo revisa en sus aspectos metodológicos, a la vez que explora su potencial alcance como instrumento para identificar paisajes culturales y sugerir intervenciones. En concreto, en lo que sigue se analiza el marco instrumental que permite actuar en materia de paisajes culturales y su inventario: el Plan PAHIS 2004-2012, promovido por la Junta de Castilla y León, y su relación con el Plan Nacional de Patrimonio Industrial. El paso siguiente es el análisis de la finalidad, los componentes y el desarrollo de los inventarios provinciales de patrimonio industrial castellano y leonés. Por último, se reflexiona sobre el alcance de las propuestas de intervención en aras a proteger, conservar y poner en valor los paisajes industriales heredados, con referencia más precisa a los resultados de los inventarios de las provincias de Zamora y Soria, donde la autora ha tenido una intervención directa.

\section{LOS INSTRUMENTOS DE INTERVENCIÓN}

\section{I.1. Planteamientos y objetivos instrumentales}

En Castilla y León la protección tiene como referente el Plan de Intervención en el Patrimonio Histórico y Artístico (PAHIS), con vigencia desde el año 2004 
hasta 2012. Su ámbito de actuación se centra, en el marco de la Ley 12/2002, de 11 de julio, de Patrimonio Cultural de Castilla y León, en todo el patrimonio histórico y cultural tangible, en los aspectos del patrimonio intangible que en él se determinan y en los bienes mixtos culturales y naturales. El objetivo básico del Plan PAHIS es proteger y conservar el patrimonio así como fomentar su conocimiento y difusión. La sostenibilidad se garantiza con objetivos tales como limitar su utilización exclusiva y abusiva como recurso económico, y lograr un equilibrio entre patrimonio y actividad turística y de ocio, evitando la sobrecarga y estableciendo pautas para el uso de los bienes integrantes del patrimonio. Por lo que respecta al patrimonio industrial, el Plan PAHIS contempla acciones específicas englobadas en un Plan Sectorial con cinco programas, entre los que destaca la elaboración del Libro Blanco del Patrimonio Industrial, encargado a una mesa de expertos coordinada por la Dirección General de Patrimonio, responsable de fijar los criterios y las prioridades que deben orientar las intervenciones en el patrimonio industrial de la región.

Desde la perspectiva del Plan PAHIS la herencia industrial se configura como un componente más del patrimonio cultural. Ahora bien, no se trata de un conjunto de elementos homogéneo, como admite el propio Plan; más bien al contrario, el patrimonio industrial destaca por "su gran diversidad tipológica, derivada de las materias primas utilizadas, de las diferentes fuentes de energía, de los grados de mecanización, de las características constructivas, de los procesos de producción, de los bienes producidos, del sistema de comercialización y de los sectores sociales implicados, entre otros" (JCyL 2005, p. 89). Por otra parte, al estar sujeto a las mejoras tecnológicas es frecuente la superposición de diferentes sistemas de producción, lo que puede implicar la alteración y transformación de numerosos bienes, cuando no la desaparición total de los más antiguos y obsoletos para dejar paso a unidades de producción más modernas; o a infraestructuras de transportes y comunicaciones de nuevo trazado; o a espacios residenciales y equipamientos en la ciudad que hacen desaparecer las viejas fábricas. Por todo ello se hace necesario intervenir con un triple objetivo: proteger, conservar y poner en valor los restos industriales.

En consecuencia, el Plan PAHIS se propone organizar y planificar una estrategia coherente y coordinada con el resto de los planes generales y sectoriales del patrimonio cultural mediante programas que abarcan desde la elaboración de directrices de análisis, documentación, información y definición de propuestas, hasta la realización de inventarios provinciales como herramienta básica para la protección, definición de uso y planificación de las intervenciones, pasando por aplicar figuras de protección, tipo BIC, y elaborar materiales y recursos didácticos a partir de los trabajos de documentación y catalogación. Sin olvidar 
los inventarios en las comarcas mineras, así como intervenir en las instalaciones fabriles más representativas de la industria regional.

\section{I.2. Concepto y criterios sobre patrimonio industrial}

Respecto al concepto de patrimonio industrial que sirve para fijar objetivos y acciones, se apuesta por una definición flexible con un contenido que abarca todos los componentes posibles: desde elementos mueble e inmueble hasta documentación escrita, gráfica, audiovisual y oral. En la delimitación del concepto se tuvo en cuenta el factor temporal, es decir, el tiempo histórico, los límites cronológicos, asumiendo que la industrialización varía de fechas en unos lugares y otros y en el caso de Castilla y León es un proceso, en general, tardío y débil, comparado con otros territorios. Por último, la escala y la dimensión territorial adquieren protagonismo frente a los criterios descriptivos al uso, que aíslan los elementos de su entorno.

Sobre los criterios de delimitación y clasificación se aúnan las dimensiones histórica, técnica, social y geográfica del patrimonio industrial y se opta por una delimitación inspirada en las legislaciones más avanzadas, arriba citadas, y en el propio Plan Nacional. Así, el patrimonio industrial de Castilla y León lo integran "el conjunto de bienes muebles e inmuebles y de bienes materiales e inmateriales que constituyen testimonios significativos de la evolución de las actividades productivas y técnicas orientadas a la explotación industrial y su influencia sobre el territorio y la sociedad" (JCyL, 2005). Son bienes inmuebles de carácter patrimonial las fábricas, las edificaciones y las instalaciones que dan testimonio de sistemas vinculados a la producción industrial, hayan perdido o no su sentido práctico y su utilidad. Son bienes muebles de carácter industrial las máquinas, los vehículos, los instrumentos, los archivos documentales y las piezas de ingeniería utilizados por la industria y/o en el proceso de industrialización (ibídem).

Se descarta implícitamente una clasificación meramente sectorial de los bienes patrimoniales por ser descriptiva y poco explicativa del proceso de industrialización de un territorio en el que normalmente están presentes más de un tipo de actividad o rama de la industrial. Esto no implica obviar el renglón de "tipo de actividad" en la ficha correspondiente al bien industrial que se vaya a inventariar y catalogar. En general, se considera que es más interesante ligar el patrimonio industrial a un contexto socioeconómico y espacial concreto que atender a criterios de afinidad productiva, si bien cada bien patrimonial llevará la "etiqueta" de la actividad a la que pertenece. Asimismo, se descarta el criterio puramente cronológico para clasificar el patrimonio industrial ya que con frecuencia una fábrica sufre reformas con el paso del tiempo o un paisaje industria reúne elementos de diferentes etapas. Para establecer áreas temáticas la Junta de 
Castilla y León toma como referencia la clasificación del Plan Nacional, que distingue entre patrimonio genuinamente industrial y conjuntos y elementos arquitectónicos vinculados al patrimonio industrial (colonias y viviendas obreras; almacenes; chimeneas; otros).

Sobre los criterios de valoración y selección, también se siguen las directrices del Plan Nacional: bienes industriales representativos de los diversos sectores industriales, de las diferentes etapas de industrialización y de los diferentes territorios; valor testimonial, singularidad-representatividad, autenticidad e integridad; valor histórico-social, tecnológico, artístico-arquitectónico y territorial; y, por último, viabilidad de la restauración, estado de conservación y situación jurídica.

\section{IMPORTANCIA Y CARACTERÍSTICAS DE LOS INVENTARIOS DE PATRIMONIO INDUSTRIAL}

Entre los objetivos del Plan PAHIS figura, como se ha visto, disponer de un inventario del patrimonio industrial de la región. Esto es así porque éste y cualquier otro instrumento de intervención en el patrimonio cultural sólo pueden alcanzar sus fines cuando se dispone de un registro o inventario de los elementos y bienes susceptibles de protección, conservación y puesta en valor. Lo más frecuente es que tales inventarios no existan o se limiten a meros listados de carácter parcial, por lo común elaborados para promover alguna intervención aislada o para crear conciencia del valor de estos recursos en ámbitos locales.

Dicha iniciativa tiene como precedente el inventario del patrimonio industrial histórico de Segovia, realizado en 2001 bajo el patrocinio de la Consejería de Cultura y Turismo de la Junta de Castilla y León. Este documento se puso al día en 2006 y a él se sumó en el mismo año el inventario de la provincia de Ávila (ambos publicados en fecha reciente como se comprueba en el capítulo de bibliografía). En 2007 se adjudicaron los inventarios de Zamora, Valladolid y Palencia, ya ejecutados, y en 2008 empezaron los trabajos de los inventarios de Salamanca, Soria y Burgos, concluidos a principios de 2009. Queda pendiente de adjudicar el inventario de la provincia de León. El aspecto más interesante de estos inventarios, además obviamente de los resultados que ofrecen y su utilidad para planificar intervenciones, es la metodología. Sobre tal cuestión se ha obtenido un modelo relativamente homogéneo que, aunque deja poco margen a los equipos redactores, es una garantía de que una vez completados los inventarios de las nueve provincias se podrán hacer comparaciones, cruzar datos y concebir acciones de conjunto, si bien queda pendiente la tarea de unificar toda la información en un inventario regional. 
Los inventarios se plantean, en general, como un trabajo que se apoya en fuentes bibliográficas, material de archivo y trabajo de campo, imprescindible éste ultimo para reunir toda la información que está dispersa, y es poco y mal conocida, sobre los elementos, conjuntos y paisajes que las actividades preindustrial e industrial han legado a unas provincias y otras a lo largo de más de dos siglos. El propósito de los equipos redactores es que el inventario sea una herramienta que permita conocer la magnitud, el valor y el estado del patrimonio histórico industrial, a la vez que un instrumento apto para tomar decisiones y poner en marcha acciones o medidas relacionadas con la conservación, protección y puesta en valor de una herencia importante como recurso del territorio y componente del paisaje (CAÑIZARES, 2009).

Cuadro 1. Estructura de los inventarios provinciales de Castilla y León

Elementos que componen los inventarios provinciales

1. Conjunto de fichas sobre cada elemento o bien patrimonial registrado, según modelo adaptado de las Prescripciones Técnicas.

2. Base de datos EXCEL con los datos esenciales, que permitirá obtener diversos listados.

3. Memoria o Informe final.

4. Sistema de Información Geográfica (SIG).

5. Anexos:

-Anexo Documental (bibliografía, documentos de archivos, etcétera)

-Anexo Fotográfico (fotografías digitales de los elementos inventariados)

-Anexo Cartográfico (mapas, planos, croquis, ortofotos, etcétera)

-Anexo Testimonios Orales y Audiovisuales (grabaciones, vídeos).

Fuente: Elaboración propia.

Dado que los inventarios tienen una clara dimensión territorial, pues se trata de registrar elementos y bienes edificados, elementos construidos, paisajes e infraestructuras y otros vestigios inmuebles distribuidos por zonas urbanas y rurales, las metodologías hacen hincapié en la necesidad de que se aporten referencias geográficas precisas y en la conveniencia de organizar el trabajo de campo con criterios que atiendan a la extensión del territorio a cubrir y a la densidad o volumen del patrimonio que se supone que existe tras el oportuno rastreo documental. Así, en las fichas aparecen los códigos de identificación del INE para situar geográficamente todos y cada uno de los elementos del inventario: provincia 2 dígitos; municipio 3 dígitos y localidad 4 dígitos. Para precisar la ubicación de cada uno de los elementos y bienes inventariados se recurre a las coordenadas geográficas (longitud, latitud y altitud) y a las coordenadas UTM, más una fotografía aérea y un mapa de ubicación (escala 1.50.000). Si es necesario se aporta la referencia catastral. La cartografía básica es el Mapa Topográfico Nacional editado por el Instituto Geográfico Nacional, indicándose en las 
fichas el nombre de la hoja, su número y escala, que en ocasiones puede ser $1: 25.0000$.

Se considera conveniente, sobre todo para gestionar la base de datos de los inventarios, identificar la actividad de los elementos patrimoniales con el correspondiente código de la Clasificación Nacional de Actividades Económicas (CNAE, 1993). La metodología de los inventarios busca, asimismo, caracterizar con precisión el elemento o bien registrado, para lo que ofrece cinco conceptos de clasificación:

$\checkmark$ Paisaje: hace referencia a un espacio más o menos amplio en el que están presentes la industria, las infraestructuras de transporte y comunicaciones a su servicio, poblados y colonias obreras, entorno natural y/o entorno urbano.

$\checkmark$ Complejo: recinto fabril que reúne distintos edificios con funciones complementarias. El conjunto define la fábrica en cuestión. Se realiza una ficha de cada elemento significativo.

$\checkmark$ Unidad: una fábrica monoplanta; o una nave; o un taller; un molino; un batán, etc.

$\checkmark$ Máquinas y mecanismos: se encuentran por lo común dentro de las fábricas o edificios productivos; pero pueden aparecer solos, fuera de su lugar o contexto original. Forman parte de la historia técnica o tecnológica de una determinada actividad industrial.

$\checkmark$ Elementos aislados: son restos de cualquier actividad industrial, minera o de transporte: desde una chimenea, hasta un castillete o un puente.

Las posibles relaciones funcionales entre los elementos y bienes de unas fichas y otras quedan registradas en tres apartados u opciones compatibles entre sí y enunciadas del siguiente modo: Pertenece a: Se indica el código del elemento o bien del que forme parte el registro de la ficha; Incluye: Se indica el código del elemento o bien que incluye el de la ficha; Relacionado con: Se indica el código del elemento o bien con el que está relacionada la ficha.

En otro orden, las fuentes bibliográficas, documentales y cartográficas se completan con el registro de testimonios orales. La naturaleza misma de esta clase de inventario, referido al patrimonio industrial histórico y a los vestigios preindustriales, exige tomar en consideración el recurso a los testimonios orales, es decir, al relato de las personas que conservan la memoria de cómo era un elemento, bien o ingenio industrial y saben, además, explicar cómo se organizaba la producción y el trabajo o cómo funcionaba una máquina determinada. 
Las fuentes orales tienen interés cuando no es posible disponer de publicaciones ni de documentación escrita (en archivos) sobre determinados bienes patrimoniales. Hay que apuntar, no obstante, que se trata de una fuente subjetiva, que puede aportar datos e información errónea y que no siempre es posible contrastar. Los equipos redactores recurren a estos testimonios siempre que no exista otro tipo de fuente o documentación escrita. Es decir, para cubrir lagunas documentales. El método de registro consiste en grabar la conversación con el informante o realizar un vídeo de su relato, con su previo consentimiento. Las grabaciones y vídeos obtenidos formarán parte del inventario.

La valoración de los bienes, conjuntos y paisajes industriales se realiza tomando en consideración los siguientes aspectos:

$\checkmark$ Criterio geográfico: análisis de la distribución por comarcas de los elementos y conjuntos patrimoniales inventariados, poniendo el énfasis en la concentración/dispersión de los mismos y en la relación que el reparto territorial tiene con respecto a ámbitos urbanos, periurbanos y rurales.

$\checkmark$ Criterio tipológico: análisis de patrimonio industrial provincial según categorías o grupos sectoriales. Se trata de determinar qué tipos predominan, dónde se localizan y la relación entre ellos.

$\checkmark$ Criterio cronológico: análisis de la edad de los elementos, bienes, conjuntos y paisajes industriales atendiendo a la fecha de construcción o puesta en marcha de los mismos.

$\checkmark$ Criterio de uso: análisis del patrimonio histórico de la provincia según su estado actual: uso original, nuevo uso, abandonado.

Cada inventario se compone de un número variable de fichas, en torno a 400, que permiten obtener una base de datos sintética que cruza información, a su vez reflejada en un SIG y completada con archivos de documentación escrita, imágenes y audiovisuales. Los equipos de trabajo están coordinados y dirigidos por expertos de distintas disciplinas (Arquitectura, Historia del Arte, Geografía) y cuentan con técnicos para las labores de campo y documentación, siendo fundamental la entrevista y los contactos con informantes locales, que guían la búsqueda y aportan datos e información relevante. En este punto hay que destacar la presencia de geógrafos en todos los grupos de trabajo y en funciones de dirección y coordinación.

En suma, los inventarios se están ejecutando a buen ritmo, con pautas generales comunes a todas las provincias (aunque será preciso uniformizar los resultados en una fase posterior y crear una base regional única) y por parte de equipos multidisciplinares que alcanzan la adjudicación del proyecto en concurso públi- 
co, siendo mayoría los equipos con presencia de la Universidad y un papel activo de los geógrafos. Los trabajos se coordinan desde la Dirección General de Patrimonio, que mantiene reuniones periódicas con los responsables de los distintos inventarios y supervisa los resultados parciales y finales de cada provincia. La ficha tiene un carácter exhaustivo y recoge información detallada del bien patrimonial, su localización precisa, su historia, estado de conservación, maquinaria que pudiera contener, fuentes para documentar su origen y funcionamiento, así como un diagnóstico de estado y una propuesta de actuación que servirá a la Administración promotora para la toma de decisiones. En tal sentido es importante anotar que la protección y las acciones que se plantean en los inventarios podrían ser vinculantes al establecer medidas de ordenación del territorio, planificación urbanística o desarrollo local.

\section{EL VALOR CULTURAL DE LOS PAISAJES INDUSTRIALES: SORIA Y ZAMORA}

El análisis de los elementos y bienes inventariados en las provincias de Soria y Zamora pone de relieve la existencia de un patrimonio, en general, modesto, diverso y desigual desde el punto de vista de su naturaleza, estado de conservación y potencial como recurso cultural. Una parte de este patrimonio son edificios, fábricas e infraestructuras que tienen un valor intrínseco derivado de su antigüedad, originalidad constructiva, maquinaria, historia del trabajo e historia de la técnica. Otra parte del patrimonio industrial está ligado al etnográfico y remite a unos sistemas de producción propios del medio rural y de la explotación del medio por el hombre en etapas preindustriales, como es el caso de los abundantes molinos y aceñas, las norias o los hornos de cal.

En la provincia de Soria destacan las fraguas, muy numerosas en la provincia, ya que cada pueblo tiene la suya; las fábricas, en su mayoría ligadas a la producción de alimentos para consumo humano (harinas, azúcar, gaseosas); las tejeras, las lonjas y los lavaderos de lana, en general mal conservados y abandonados en parajes con un paisaje en el que dominan los elementos de la economía rural.

Otros vestigios patrimoniales adquieren relevancia cultural en tanto en cuando forman parte de un conjunto que reúne varias unidades de un mismo tipo de bien, entre las cuales unas se conservan mejor que otras. Incluso algunos elementos pueden estar restaurados y otros en ruina. Pero lo interesante aquí es que son construcciones de igual tipo y función productiva, que proliferaran en una localidad o lugar en razón de factores de localización comunes (materias primas, energía, fuerza de trabajo, mercado). En este sentido destacan los molinos de Fresno de Caracena, los de Lumías y los de Aguilera; elementos que sin 
llegar a definir paisajes en por sí mismos permiten desarrollar argumentos para crear espacios de contenido cultural.

El tercer grupo patrimonial destacado en Soria lo constituyen precisamente elementos integrados en un paisaje al que aportan originalidad y valores culturales específicos. Sobresalen en este sentido el paisaje que definen las canteras

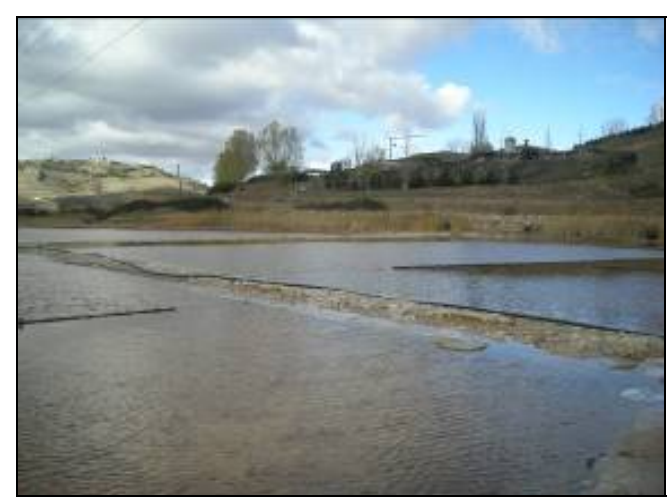

Fig. 1. Paisaje cultural de las salinas de Medinaceli (Soria). de San Felices (comarca de Ágreda) o los lagares y bodegas de Atauta.

Hay que señalar que los paisajes inventariados no tienen porqué estar constituidos por elementos patrimoniales de la misma tipología; pueden ser paisajes integrados por una amplia variedad de elementos que conviven en un lugar y son resultado de un proceso de industrialización que altera el espacio preexistente para conformar un nuevo paisaje que con el

tiempo deviene en cultural. En tal sentido destaca el paisaje de ribera de la ciudad de Soria: en un tramo del río Duero de no más de dos kilómetros se concentran de forma sucesiva fábricas de harina y luz, molinos, tenerías, un puente de hierro, un lavadero y lonja de lana restaurados, un museo del agua, etcétera; en total unos 15 elementos repartidos entre las dos orillas del río y que definen un interesante paisaje cultural en una ciudad donde la industrialización fue mera anécdota.

En la provincia, Zamora, igualmente de débil industrialización, el inventario arroja un total de 305 elementos y bienes registrados en fichas agrupados en 21 categorías o clase tipológica con un reparto muy desigual. Destaca la elevada presencia de molinos, en su mayoría destinados a la molienda de cereales para consumo humano y animal. De los 305 elementos, conjuntos y paisajes inventariados 140 son molinos, es decir, casi el $46 \%$ del total. Le siguen en importancia numérica las fraguas, 37 fichadas, que representan el 12,13\% del total inventariado. En consonancia con la abultada presencia de molinos, las fábricas de harina suman 23 elementos, es decir, un 7,54\% de total inventariado. Por detrás de estos elementos, son importantes en número los lagares $(5,25 \%)$ y los hornos de pan $(4,26 \%)$. Las tipologías con menor presencia y representación en Zamora son las fundiciones, el martinete o las fábricas de chocolate y gaseosas, con un 
elemento cada una $(0,33 \%$ del total). En una posición numérica intermedia hay que situar las tejeras y las infraestructuras ferroviarias, con 8 elementos en cada caso (que representan el 2,62\%); le siguen los aserraderos, 6 elementos $(1,97 \%)$ y las fábricas de luz, 5 elementos que representan el 1,64\% del total inventariado.

En conclusión, la familia de las fábricas (todas las variantes reflejadas en las fichas, excepto las de harinas), comprende 13 elementos o conjuntos que representan tan sólo el 4,26\% del total, la familia con menor presencia en el patrimonio zamorano. Una segunda familia, la más nutrida, se compone de molinos, harineras y aceñas, y aquí el número de bienes inventariados se eleva a 163, el $53,44 \%$ del total, es decir, más de la mitad del Inventario. La familia de fraguas y fundiciones también tiene una representación destacada ya que concentra 38 elementos, el 12,46\%. Los ingenios, familia integrada por 24 elementos, tiene una presencia modesta, el 7,87\%. La última categoría o familia es un grupo variado de elementos, otros, donde caben todos los que no encajan en las familias anteriores: es numeroso, 67 elementos y bienes, es decir, casi el $22 \%$ del total, lo que significa que existe una amplia variedad de elementos y bienes poco o muy poco representados, como es el caso de los laboratorios, las tejeras, los hornos de cal, los mataderos, las presas, los complejos mineros o los aserraderos y telares.

Entre los elementos o conjuntos patrimoniales que crean paisaje destacan las norias, que suelen aparecer en campos abiertos, separadas unas de otras, pero formando conjuntos que se integran en un espacio agrario que contiene los elementos de un paisaje cultural de alto interés patrimonial, como interesante es, en

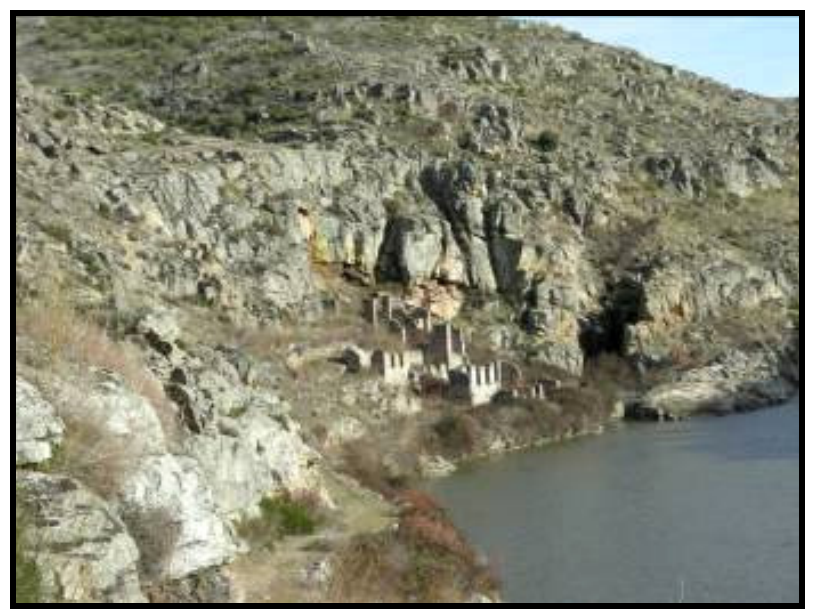

Fig. 2. Paisaje minero de Almaraz de Duero, Zamora. términos de cultura campesina, la costumbre de los vecinos de usar de manera colectiva y organizada estos ingenios, ligados al riego de las tierras y al consumo de agua para mantener el ganado. También hay que hacer notar la singularidad del paisaje minero de Almaraz de Duero, único en la provincia, que ofrece 
los restos de una vieja explotación de estaño en un medio de notable valor natural y cultural. $\mathrm{O}$ el paisaje que brindan las antiguas explotaciones de sal en el entorno de las Lagunas de Villafáfila, explotaciones hoy desaparecidas, pero documentadas y narradas en un centro de interpretación que rescata la memoria de una actividad que fue fundamental en la vida económica de la provincia, desde la Edad Media hasta los tiempos modernos. Por último, en esta categoría de paisajes culturales podemos incluir la presa de Ricobayo y su entorno, un elemento adscrito a la ingeniería del agua que transforma el espacio que ocupa y sus inmediaciones, dando lugar a un pintoresco conjunto paisajístico de rasgos culturales.

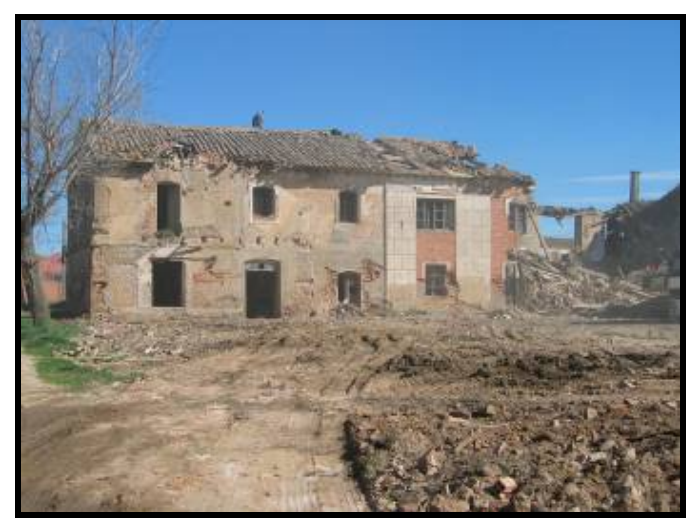

Fig. 3. Restos de la Real Fábrica de Salitres en Villafáfila, Zamora.

\section{CONCLUSIÓN}

Los elementos y bienes vinculados a las actividades industriales cobran protagonismo en las políticas de patrimonio cultural, bien porque se trata de una herencia valiosa como recurso y valorada socialmente; bien porque forman parte de paisajes urbanos o rurales que, en atención a recomendaciones como las contenidas en el Convenio

Europeo del Paisaje (Florencia 2000), se integran en las estrategias regionales y locales de desarrollo territorial. Esa creciente importancia de los vestigios de la industrialización tiene eco en las actuaciones que la Junta de Castilla y León lleva a cabo en materia de patrimonio. Así, los paisajes industriales y los vestigios de la industrialización repartidos por las distintas provincias de la Comunidad Autónoma, reconocidos todos como patrimonio industrial, son objeto de un minucioso registro y análisis. Dichos inventarios brindan una metodología rigurosa, aunque mejorable, que da resultados satisfactorios y útiles en la toma de decisiones, tal y como aquí se ha intentado demostrar. A su vez, son una herramienta que puede orientar las políticas de ordenación del territorio y de planificación, pues identifican paisajes y construcciones que deben protegerse y son susceptibles de poner en valor.

\section{BIBLIOGRAFÍA Y DOCUMENTACIÓN}

AlONSO IBAÑEZ, M. R. (2002): «Aspectos normativos del patrimonio industrial», en AA VV, Patrimonio industrial: lugares de la memoria. Gijón, Incuna, 109-127. 
Benito Del Pozo, P. (dir.) (2008): Territorio y patrimonio industrial en Castilla y León. León, Universidad de León.

BENITO DEL POZO, P. (2009): «El valor del paisaje en los inventarios de patrimonio industrial de Castilla y León», en ACTAS XXI Congreso de Geógrafos Españoles. Ciudad Real, AGE y Universidad de Castilla-La Mancha (soporte CD).

BIEL, M. P. (2007): Actas Jornadas de Patrimonio Industrial y Obra Pública. Zaragoza, Gobierno de Aragón (en soporte CD).

CAÑIZARES, M. C. (2009): «El patrimonio industrial: un recurso del territorio y un componente del paisajes», en V Congreso TICCIH-España. Interpretación, Documentación y Gestión del Patrimonio en el Paisaje Industrial y Cultural (en soporte CD).

FERNÁNDEZ, M. F. (1998): «La labor de inventario del patrimonio industrial en Francia. Un modelo de investigación, protección y difusión», Ábaco. Revista de Cultura y Ciencias Sociales, 19, 59-70.

Instituto del PATRIMONIO CUltural De EsPaÑA: Plan del Patrimonio Industrial. En línea: $<$ www.mcu.es/patrimonio $>$.

Junta de CAStilla y León (2005): Plan Pahis 2004-2012 del Patrimonio Histórico de Castilla y León. Consejería de Cultura y Turismo, Dirección General de Patrimonio y Bienes Culturales.

JunTA DE CASTILLA Y LEÓN (2008): Inventario del Patrimonio Histórico Industrial de la Provincia de Segovia. Valladolid, Consejería de Cultura y Turismo.

JUNTA DE CASTILLA Y LEÓN (2008): Inventario del Patrimonio Histórico Industrial de la Provincia de Ávila. Valladolid, Consejería de Cultura y Turismo.

Ministerio de Cultura (2008): Convenio Europeo del Paisaje. Florencia, 20 de octubre de 2000. Madrid, Secretaría General Técnica. 